\title{
Geologia
}

\section{Os Anfibolitos do Complexo Costeiro na Região de São Sebastião, SP}

\author{
The Amphibolites of the Costeiro Complex in the São Sebastião Region, SP
}

\author{
Coriolano de Marins e Dias Neto' (coridias@usp.br), Ciro Teixeira Correia' (ccorrei@usp.br), \\ Colombo Celso Gaeta Tassinari' (ccgtassi@usp.br), Jose Manuel Urbano Munhá (jmunha@fc.ul.pt) \\ 'Departamento de Mineralogia e Geotectônica - Instituto de Geociências - USP \\ R. do Lago 562, CEP 05508-080, São Paulo, SP, BR \\ ${ }^{2}$ Departamento de Geologia - Faculdade de Ciências - Universidade de Lisboa, Lisboa, PT
}

Recebido em 02 de julho de 2009; aceito em 31 de agosto de 2009

\section{RESUMO}

O Complexo Costeiro na região de São Sebastião, Estado de São Paulo, como segmento da Faixa de Dobramentos Ribeira, integra os setores paraderivados a leste e ortoderivados a oeste, organizados segundo uma estrutura de cisalhamento dúctil em flor positiva. O eixo desta estrutura, que se orienta ENE-WSW, aloja as principais ocorrências dos corpos anfibolíticos que ocorrem no interior dos predominantes granada-gnaisses paraderivados. As rochas básicas intrusivas, que deram origem a estes anfibolitos, alojaram-se em estruturas tabulares ou em câmaras magmáticas secundárias, que localmente ainda preservam características geoquímicas de toleiitos continentais. Determinações U-Pb (SHRIMP) em zircão indicam idade de 580 Ma para esse magmatismo. Idades de 570 Ma para determinações equivalentes em sobrecrescimentos de cristais detríticos de zircão, dos paragnaisses encaixantes, retratam a proximidade entre o magmatismo básico e o ápice do processo metamórfico regional, favorecendo a interpretação do ambiente tectônico de colocação como sendo uma bacia sedimentar de retroarco sobre crosta continental. As áreas-fonte envolveriam rochas diferenciadas entre o Paleoproterozoico e o Neoproterozoico. A localização dos núcleos anfibolíticos, ao longo do eixo da estrutura em flor, assim como o posicionamento das manifestações magmáticas do Mesozoico, parecem conferir a esta estrutura uma importância especial, podendo ter favorecido a recorrência de eventos geológicos.

Palavras-chave: Complexo Costeiro; Faixa de Dobramentos Ribeira; Ciclo Brasiliano.

\begin{abstract}
Geochronological, petrographic and lithochemical data have been used to characterize the crustal evolution and the thermochronology of the Costeiro Complex, São Paulo State, Brazil. This part of the Ribeira Fold Belt is composed of paraderived rocks to the East, and orthoderived rocks to the West, which are organized along a ductile shear zone forming a positive flower structure whose axis runs ENE-WSW. The main amphibolite occurrences are found within predominant garnet-paragneisses along this axis. The age of crystallization of the intrusive basic magmas which originated the amphibolites was $580 \mathrm{Ma}$ (U-Pb SHRIMP). They formed tabular intrusions or secondary magma chambers, that locally still preserve continental tholeiitic geochemical characteristics. The close proximity of the basic magmatism and the metamorphic peak is evident from the $570 \mathrm{Ma}$, U-Pb age determination of the overgrowths on detritic zircon crystals in the paragneisses. This suggests a tectonic environment where the basic magmas intruded a back-arc sedimentary basin established over continental crust. The source areas were probably rocks differentiated from the mantle between the Paleoproterozoic and Neoproterozoic.
\end{abstract}

Keywords: Costeiro Complex; Ribeira Fold Belt; Brasiliano Cicle. 


\section{INTRODUÇÃO}

Pretendendo estabelecer a evolução crustal e termocronológica do Complexo Costeiro no Estado de São Paulo, Dias Neto (2001) desenvolveu trabalhos visando a caracterização geocronológica, geoquímica e petrográfica dos granada-paragnaisses e das rochas granitoides, assim como dos núcleos de rochas máficas, que ocorrem deformados e rompidos no interior de ambos. As rochas paraderivadas constituem-se nas principais unidades litológicas deste segmento da Faixa de Dobramentos Ribeira.

Os dados geocronológicos, processados em grande quantidade, envolveram os métodos U-Pb SHRIMP, em zircões, Sm-Nd e Rb-Sr, em rocha total e em concentrados minerais e K-Ar em minerais. Estes resultados, apresentados em detalhe por Dias Neto (2001), permitiram a determinação das idades de cristalização magmática e do pico metamórfico que afetou este complexo, assim como forneceram subsídios para o acompanhamento do processo de resfriamento regional que se implantou após o ápice do metamorfismo.

A análise do comportamento litoquímico das rochas anfibolíticas presentes na região estudada, como principal objetivo deste trabalho, associada às características litoquímicas das rochas graníticas comentadas em detalhe por Dias Neto et al. (2008) forneceram os parâmetros necessários à caracterização dos ambientes tectônicos relacionados à geração destas rochas.

A análise conjunta das características geoquímicas destes diferentes conjuntos de rochas, de forma integrada com os dados geocronológicos obtidos, permitiu fazer inferências sobre o contexto tectônico de formação e da evolução geológica desta região do Complexo Costeiro, em São Paulo.

\section{ÁREA DE ESTUDO}

A área de interesse deste estudo se localiza na região SE do Estado de São Paulo (Figura 1), entre os paralelos $23^{\circ} 30^{\prime}$ e $24^{\circ} 00^{\prime}$ S e meridianos $45^{\circ} 15^{\prime}$ e $46^{\circ} 15^{\prime}$ ' W, em especial, ao longo dos costões rochosos situados entre as cidades de São Sebastião e Guarujá, onde os tipos litológicos em foco se acham melhor expostos.

\section{O SETOR CENTRAL DA FAIXA DE DOBRAMENTOS RIBEIRA}

\section{Contexto Geológico Regional}

O Cinturão Móvel Ribeira (Almeida et al., 1973) ou Faixa Ribeira (Cordani et al., 1973) constitui-se em um complexo cinturão orogênico que se estende por mais de $1.400 \mathrm{~km}$ ao longo da margem atlântica brasileira. Esta importante unidade geotectônica participou do episódio de colagem, que originou a parte oeste do paleocontinente Gondwana, do Neoproterozoico ao Eopaleozoico (Brito Neves e Cordani, 1991).

Ebert e Hasui (1998) sugerem a geração da Faixa Ribeira durante o Neoproterozoico, juntamente com a Faixa Brasília, através do fechamento em junção tríplice dos blocos Vitória, São Francisco e Paraná. Os processos que orientaram estas colisões se associam a movimentos laterais, oblíquos e frontais, durante a convergência dos blocos, assim como subducção do tipo A.

A região central da Faixa Ribeira, envolvendo o sudeste do Estado de São Paulo, foi compartimentada por Tassinari e Campos Neto (1988), com base em informações geocronológicas, em três domínios tectônicos, separados por expressivas zonas de cisalhamento, dispostos, de NW para SE, em São Roque, Embu e Costeiro. O Domínio São Roque integra rochas meso a neoproterozoicas que representam uma sequência metavulcanossedimentar de baixo a médio grau, com os grupos Itaberaba na base e São Roque no topo (Juliani et al., 2000; Hackspacher et al., 2000). O Grupo São Roque tem sido interpretado por vários autores (Figueiredo et al., 1982; Bergmann, 1988; Lazzari, 1987; Hackspacher et al., 2000; Tassinari et al., 2001), em termos de ambiente tectônico, como sendo uma bacia sedimentar de retroarco sobre crosta continental. As rochas mais antigas do Domínio Embu forneceram idades de 2,5 Ga com um evento metamórfico em 1,4 Ga, migmatização a 750 Ma e geração de rochas graníticas em 700 - 600 Ma. No Complexo Costeiro as idades das rochas se situam no Neoproterozoico (600 - $650 \mathrm{Ma}$ ), com plutonismo tardi a pós-tectônico, de caráter charnockítico, a 550 Ma (Tassinari e Campos Neto, 1988). Resultados K-Ar, em minerais, segundo os autores citados, indicam que o resfriamento regional ocorreu neste domínio entre 500 - 450 Ma.

Fonseca et al. (1979), com base na interpretação tectônica dos trabalhos pioneiros de Ebert $(1957,1968)$ e Rosier (1965), estenderam os metassedimentos de fácies anfibolito que constituem o Grupo São Roque/Açungui, no Estado de São Paulo, para o Estado do Rio de Janeiro. Neste sentido, o Complexo Embu, definido por Hasui e Sadowski (1976) como o conjunto de rochas paragnáissicas-migmatíticas do Grupo Açungui, se assemelha aos litotipos que compõem o Complexo Paraíba no Estado do Rio de Janeiro, sendo que a relação entre ambos não está bem definida na literatura.

\section{Complexo Costeiro}

O Complexo Costeiro, no Estado de São Paulo, é delimitado a norte, pela Falha de Cubatão, e a sul, pela linha de costa e ilhas vizinhas (Hasui et al., 1981) (Figura 1). 

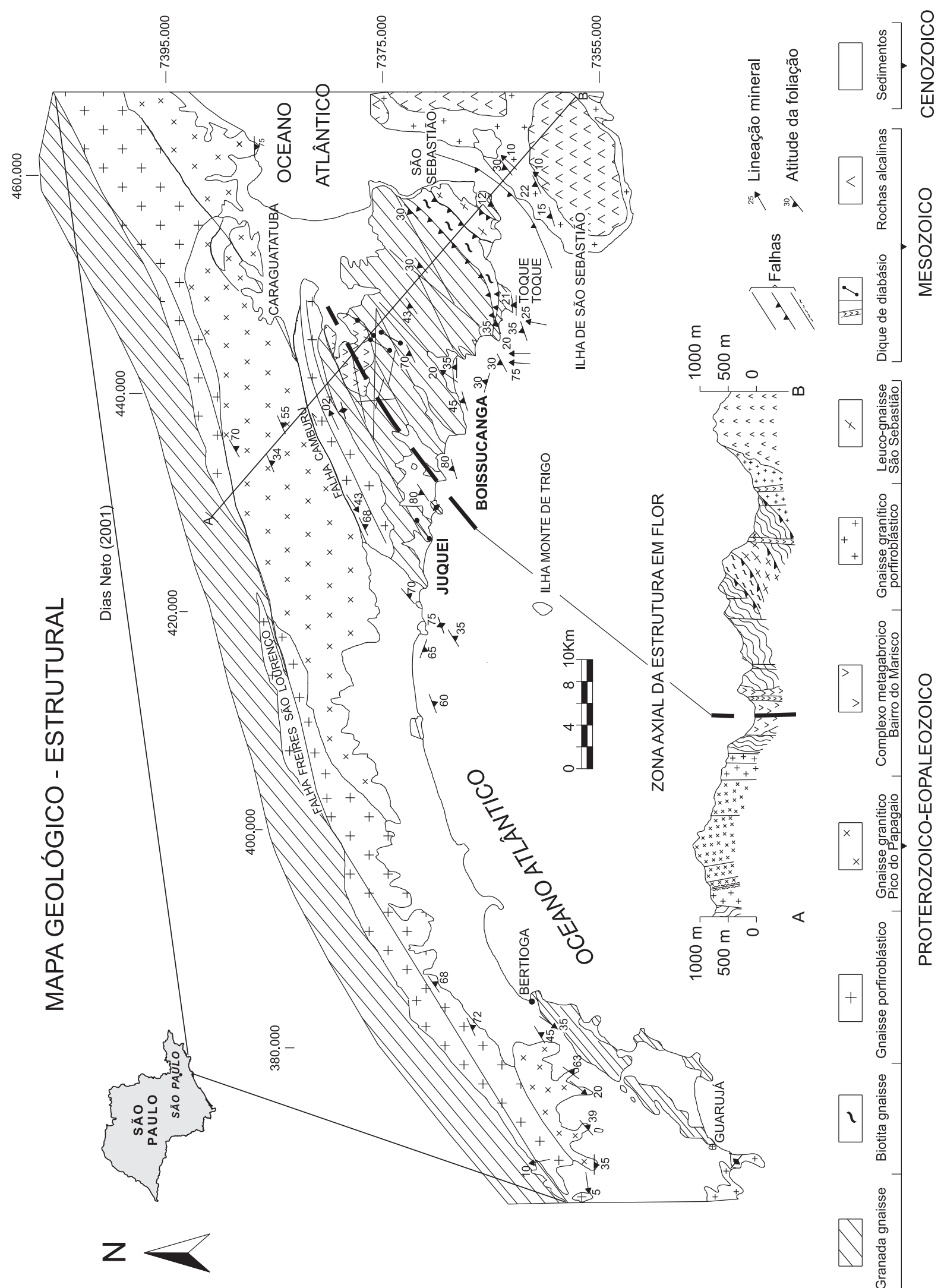

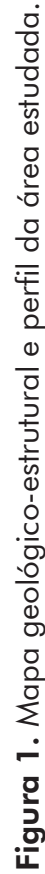


Esta unidade é constituída por três conjuntos litológicos distintos representados por sequências gnáissico-migmatíticas, para-derivadas e granulíticas (Chiodi et al., 1983; Sobreiro Neto et al., 1983).

O conjunto gnáissico-migmatítico é composto por ortognaisses variados e migmatitos com paleossoma de hornblenda-biotita gnaisse e neossoma de composição granodiorítica.

Os metassedimentos são constituídos, preferencialmente, por rochas síltico-argilosas e, subordinadamente, quartzitos arcosianos e cálcio-silicáticas. Todo o conjunto paraderivado foi submetido a intenso processo de quartzo-feldspatização durante o metamorfismo de médio a alto grau, associado ao desenvolvimento do Ciclo Brasiliano, no final do Neoproterozoico.

Núcleos centimétricos a métricos boudinados de rochas máficas-ultramáficas, ocorrem no interior dos paragnaisses, como assinalam Coutinho e Tassinari (1991) e Campanha e Ens (1993). Foi descrito por Silva et al. (1977) o Complexo Bairro do Marisco, que representa rochas metabásicas com dimensões quilométricas, situadas em meio aos paragnaisses, com estruturas interpretadas como paleodiques anfibolitizados.

As rochas granulíticas, segundo Chiodi et al. (1983), são constituídas predominantemente por charnockitos e noritos que ocorrem associados aos gnaisses oftalmíticos e aos corpos graníticos presentes na área. Os charnockitos da área são rochas ígneas que segundo Tassinari et al. (2001) apresentam gênese relacionada com os processos magmáticos associados aos granitoides que intrudiram as rochas metamórficas do Complexo Costeiro.

Batólitos graníticos, como o de Natividade da Serra e o de Caraguatatuba, e corpos menores como o charnockito de Ubatuba, são encontrados no âmbito deste domínio. Na maioria, são corpos graníticos porfiríticos, tardi a pós-tectônicos, com composição álcali-cálcica (Janasi e Ulbrich, 1992).

As principais estruturas presentes no Complexo Costeiro, no Estado de São Paulo, definem um trend ENEWSW (Chiodi et al., 1983). As rochas metamórficas apresentam uma forte e penetrativa xistosidade e/ou foliação gnáissica, em todas as escalas. Padrões de deformação impostos pelas grandes zonas de cisalhamento NE-SW, que afetaram a região, favorecem figuras anastomosadas que reorientam as estruturas, não raramente, no quadrante NW, como apresentado por Carneiro et al. (1979). Estruturas em leque relacionadas às zonas de cisalhamento dúctil, sugerindo regime transpressivo na evolução do Cinturão Ribeira, têm sido assinaladas por diversos autores (Sadowski, 1991; Ebert et al., 1991; Machado e Endo, 1993; Campanha e Ens, 1993; Ebert et al., 1993; Ebert e Hasui, 1998; Dias Neto et al., 2006).
O Complexo Costeiro, durante o Mesozoico, foi afetado por expressiva atividade magmática alcalina relacionada ao processo de fragmentação continental e de abertura do Oceano Atlântico. Determinações K-Ar obtidas para complexos alcalinos forneceram idades dentro do intervalo de 95 e 45 Ma. (Amaral et al., 1967; Ulbrich e Gomes, 1981), enquanto os diques de diabásio, normalmente concordantes com o "trend" regional e muito frequentes no interior do complexo, apresentaram idades no intervalo de 140 - 110 Ma (Minioli, 1971).

Expressivos movimentos verticais ocorreram na área, durante o Cenozoico, associados à abertura do Atlântico Sul, condicionando escarpas de falhas e favorecendo fortes processos erosivos, expondo rochas de níveis crustais profundos.

\section{O COMPLEXO COSTEIRO NA ÁREA DE ESTUDO}

O Complexo Costeiro na região estudada integra setores com rochas paraderivadas a leste, na península de São Sebastião, e com rochas ortoderivadas a oeste, entre as localidades de Juqueí e Guarujá (Dias Neto et al., 2008), organizados segundo uma estrutura de cisalhamento dúctil em flor positiva, cujo eixo se orienta ENE-WSW (Dias Neto et al., 2006). Importantes corpos de anfibolitos, que ocorrem como "boudins" no interior dos granada-gnaisses predominantes, acompanham esta orientação (Figura 1).

\section{A Unidade dos Paragnaisses}

Os paragnaisses são rochas relativamente heterogêneas que acompanham as variações típicas de uma sequência metassedimentar. Injeções de material neossomático quartzo-feldspático em estruturas migmatíticas foliadas, quando em condições dinâmicas, ou pegmatoides, quando tardias, são comuns.

O bandamento gnáissico é irregular refletindo os processos dinâmicos e migmatíticos que acompanharam a geração destas rochas, onde núcleos amendoados de litotipos mais antigos (granada-gnaisses, restitos biotíticos, cálciosilicáticas e rochas anfibolíticas) são contornados pela foliação definida pela orientação de biotitas, em especial, e de sillimanitas quando presentes, evidenciando o processo de transposição a que foram submetidas.

As texturas variam de lepidoblástica a granoblástica, com granulação de média a grossa, onde a recuperação de grãos é bastante comum e os grãos de quartzo e feldspato apresentam extinção ondulante.

A rocha gnáissica é constituída, basicamente, de plagioclásio comumente sódico, quartzo e biotita, em intervalos percentuais equivalentes. Cordierita está presente em 
vários pontos. As granadas podem alcançar alguns centímetros de diâmetro e normalmente se associam às biotitas. Assim como as sillimanitas, as granadas podem estar presentes em vários percentuais na composição da rocha. Feldspato-potássico ocorre amplamente em níveis neossomáticos, tanto na matriz quanto em fenocristais tardios, com muitas inclusões, normalmente associados à presença de sillimanitas. Muscovita pode ser encontrada com facilidade nestes níveis quartzo-feldspáticos.

Como acessórios tem-se, comumente, zircão, apatita e opacos. A maioria dos zircões presente nos metassedimentos, possivelmente detríticos, apresenta recristalização de bordas. Foram observados, localmente, cristais euédricos de zircão, possivelmente neoformados durante o processo metamórfico.

\section{OS NÚCLEOS ANFIBOLÍTICOS}

Núcleos anfibolíticos são relativamente comuns no interior das rochas gnáissicas. Estes corpos ocorrem segundo conjuntos distintos, cujas características devem refletir suas origens. Tanto o conjunto, presente prioritariamente em Boissucanga e denominado de BC, estudado por Dias Neto et al. (1999), quanto os corpos distribuídos nos costões de Juqueí, referidos aqui como JQ, são detalhados no presente trabalho.

Corpos tabulares, concordantes com a foliação gnáissica, com dobras apertadas a isoclinais e rompidos, parecem retratar antigos sills ou diques, paralelizados com o bandamento do gnaisse, pela deformação (Figura 2). Estas rochas negras e homogêneas, de granulação média a fina, ocorrem de modo frequente na área de Boissucanga. A mineralogia destas rochas apresenta mais de 50\% de hornblenda, cerca de $25 \%$ de plagioclásio, com alguns percentuais de quartzo e de biotita e tem como acessórios mais comuns, apatita, titanita, zircão e opacos. As texturas variam de granoblástica a granomematoblástica. Rochas assemelhadas a este conjunto foram descritas por Coutinho e Tassinari (1991) na Península do Baleeiro e podem ser observadas também nas localidades de Paúba, Santiago e Toque-Toque.

Outro conjunto de anfibolitos é representado por corpos máficos irregulares, interiores aos paragnaisses que foram, como os anteriores, metamorfizados e deformados conjuntamente. Estas rochas, classificadas como metagabros, apresentam granulação média a grossa e mineralogia básica com 35 - 40\% de plagioclásio, 30 - 35\% de hornblenda, 10 - 20\% de biotita, e alguns percentuais de quartzo, tendo como acessórios titanita, apatita, zircão e opacos. A textura predominante é granoblástica, entretanto, em vários pontos tem-se preservadas texturas ígneas subofíticas. Feições reliquiares de cristais de piroxênio passando a anfibólios são relativamente comuns. O plagioclásio normalmente se apresenta zonado. A principal ocorrência destas rochas encontra-se no costão W de Juqueí, onde se acham expostas por centenas de metros, fartamente injetadas por veios quartzo-feldspáticos associados à fase pegmatítica (Figura 3). Neste local, foi descrita por Coutinho e Tassinari (1991) a ocorrência de plagioclásio-hornblenda websterito, em núcleos boudinados interiores aos paragnaisses.

Configurando um corpo elíptico, cujo eixo maior, de cerca de $6 \mathrm{~km}$, se orienta próximo de ENE, o Complexo Bairro do Marisco (Figura 1), definido por Silva et al. (1977), composto de metagabros e metadioritos caracteriza-se como a maior ocorrência de rochas metabásicas associada ao domínio paraderivado. Estas rochas achamse intrudidas por diques de microdioritos pórfiros, mesozoicos. Os metagabros do Complexo Marisco apresentam granulação grossa, com cristais de hornblenda de vários centímetros, crescidos sobre uma matriz poiquilítica, englobando plagioclásio ripiforme de geminação complexa. A mineralogia básica constitui-se de clinopiroxênio, anfi-

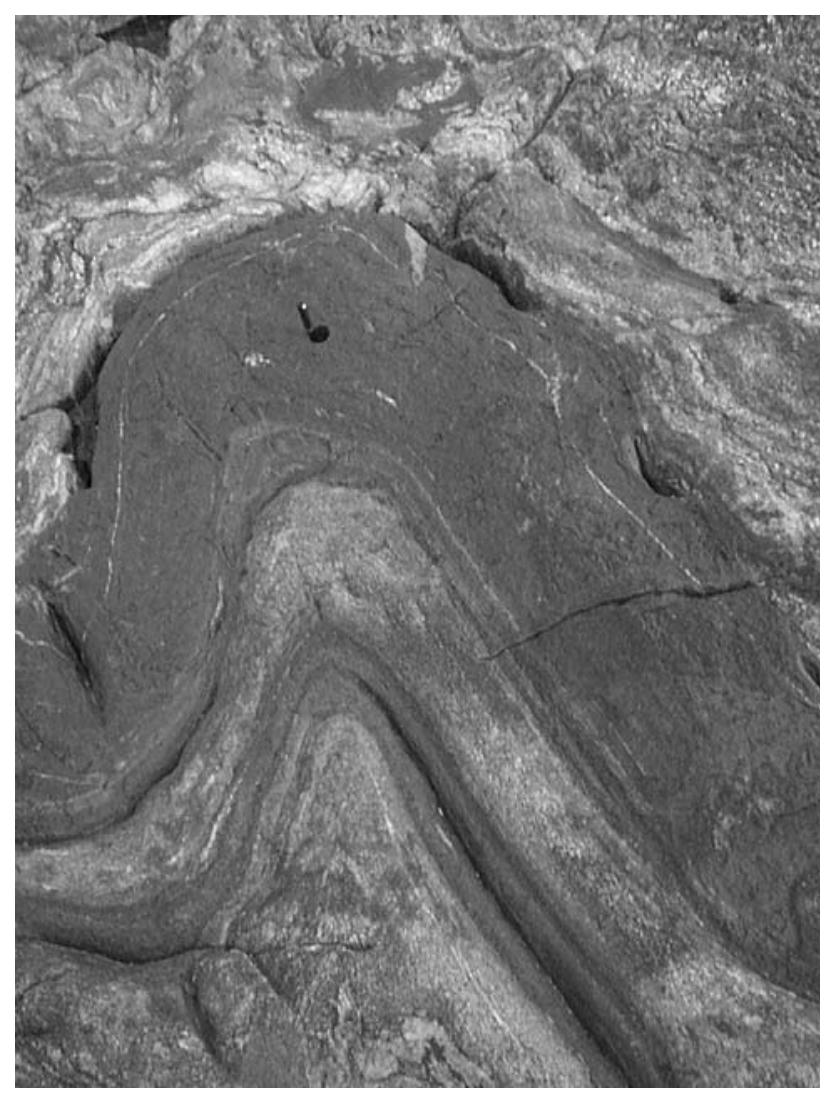

Figura 2. Corpos tabulares anfibolíticos dobrados juntamente com a estrutura gnáissica, em Boissucanga. Escala: caneta em furo de sonda de $2 \mathrm{~cm}$ de diâmetro. 


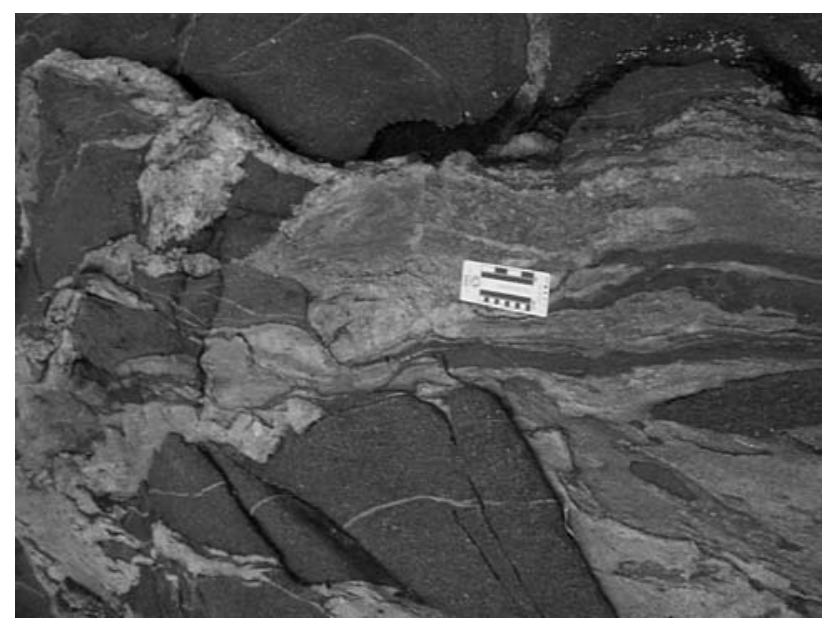

Figura 3. Núcleos metagabroicos anfibolitizados, injetados por veios quartzo-feldspáticos da fase pegmatítica, nos costões de Juqueí.

bólio, plagioclásio e ortopiroxênio. Olivina alterada cede lugar a ortopiroxênio, que por sua vez se transforma em hornblenda. O ortopiroxênio se acha em equilíbrio com o clinopiroxênio.

\section{GEOQUÍMICA DOS ANFIBOLITOS}

Através dos trabalhos de campo e análises petrográficas, foram escolhidos para análises químicas os conjuntos de rochas anfibolíticas presentes no interior dos granadaparagnaisses.

Os anfibolitos representam dois grupos que são denominados segundo os seus respectivos locais de principal ocorrência. Os BC com referência à Praia de Boissucanga e os JQ, presentes, principalmente, no costão W da Praia de Juqueí (Figura 1).

O quadro litoquímico em estudo totaliza 16 rochas anfibolíticas, assim distribuídas: 8 BC e 8 JQ (Tabela 1).

Avaliados o caráter ortoderivado, as condições de alteração e as afinidades com líquidos basálticos, não foram encontrados impedimentos para a utilização dos diagramas discriminantes e de classificação litoquímicos para as rochas anfibolíticas da área de estudo.

Apoiando-se nas relações entre sílica e álcalis, segundo Le Maitre (1989), todos os anfibolitos analisados se enquadram no campo dos basaltos da Figura 4, sendo os JQ mais ricos em sódio e potássio.

A distinção entre os dois grupos de anfibolitos pode ser observada na Figura 5, onde os BC são francamente subalcalinos, os JQ estão próximos ao limite alcalino subalcalino.

\section{Le Maitre (1989)}

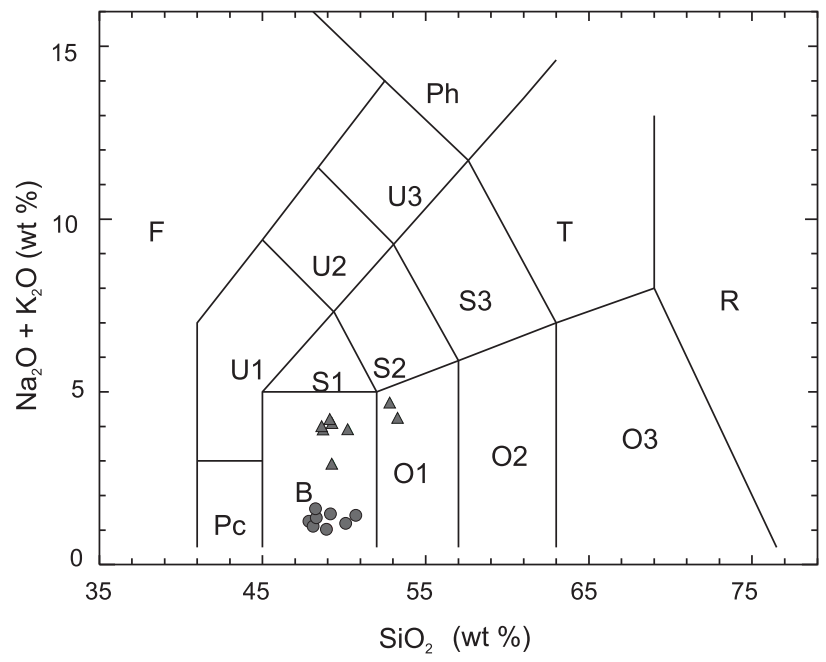

Figura 4. Classificação química das rochas metabásicas de Boissucanga BC (círculos) e de Juqueí JQ (triângulos), segundo Le Maitre (1989). B = Basalto; $\mathbf{O 1}=$ Basalto andesítico; $\mathbf{S} 1$ = Traqui-basalto; $\mathbf{S 2}=$ Traqui-andesito basáltico.

\section{Irvine e Baragar (1971)}

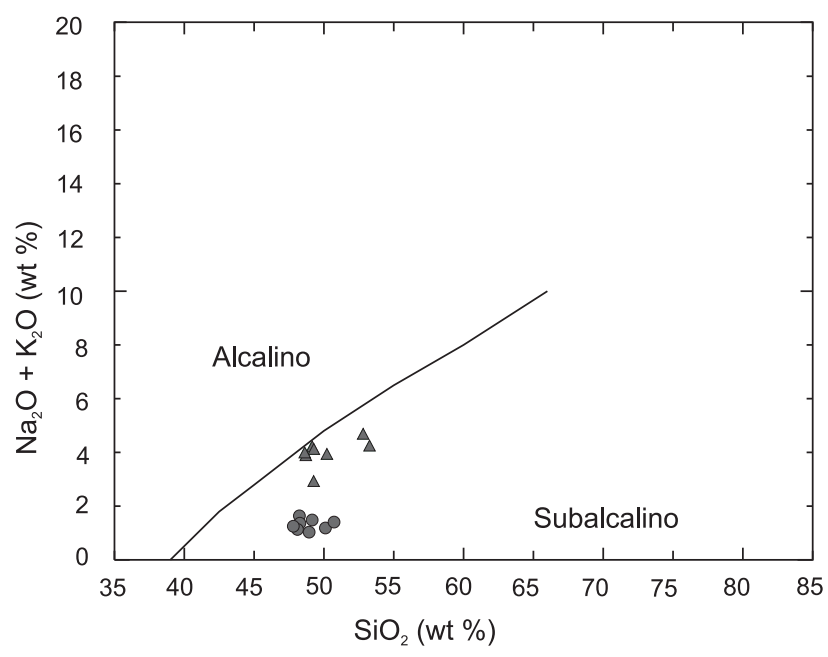

Figura 5. Diagrama sílica $x$ álcalis de Irvine e Baragar (1971), com o limite entre os campos alcalino e subalcalino, no qual se distinguem os anfibolitos de Boissucanga BC (círculos) e de Juqueí JQ (triângulos). 


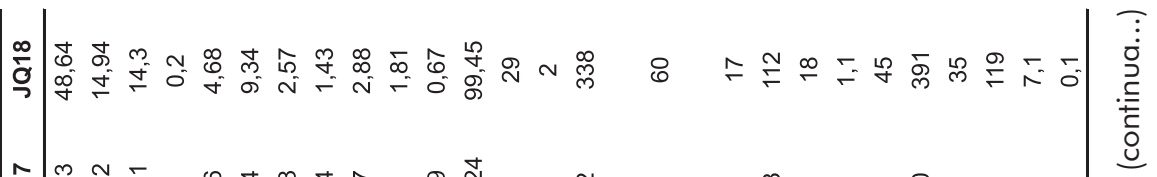

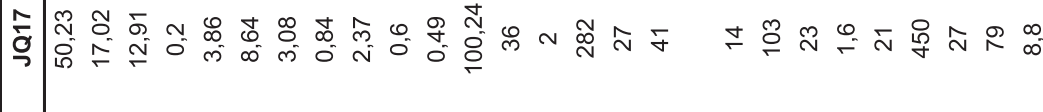

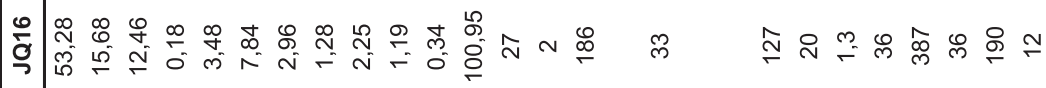

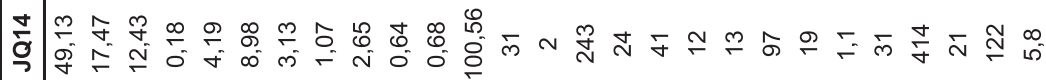

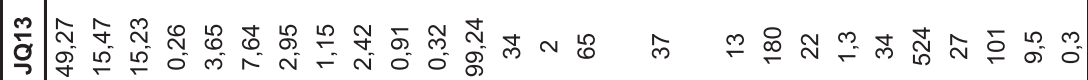

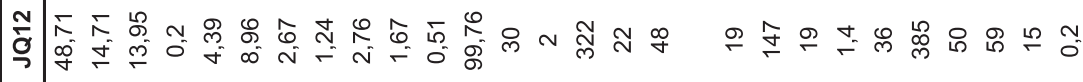

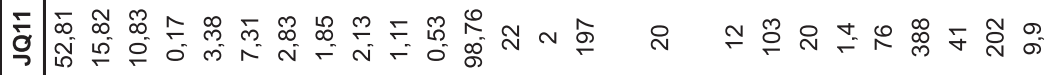

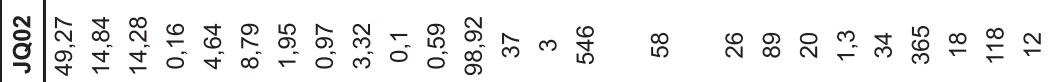

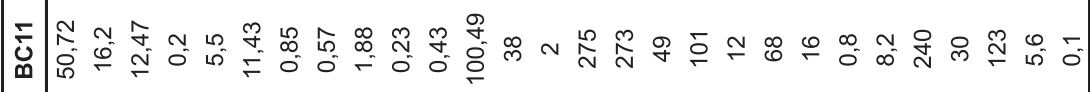

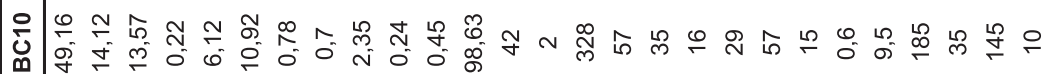

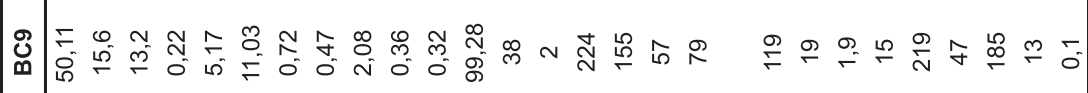

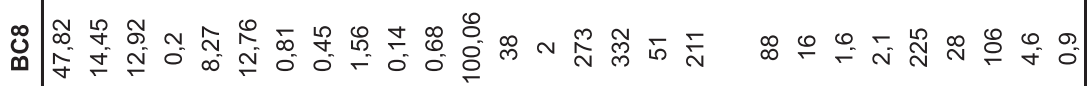

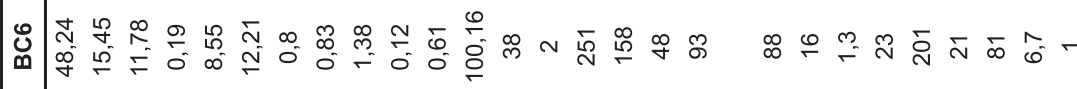

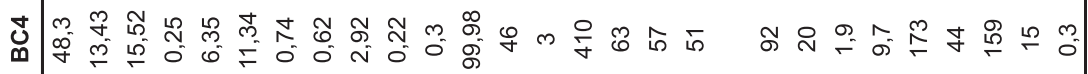

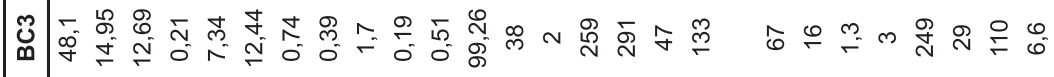

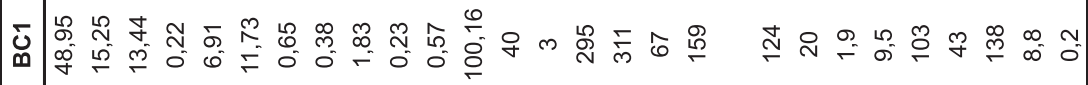

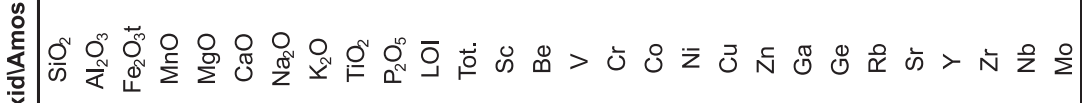




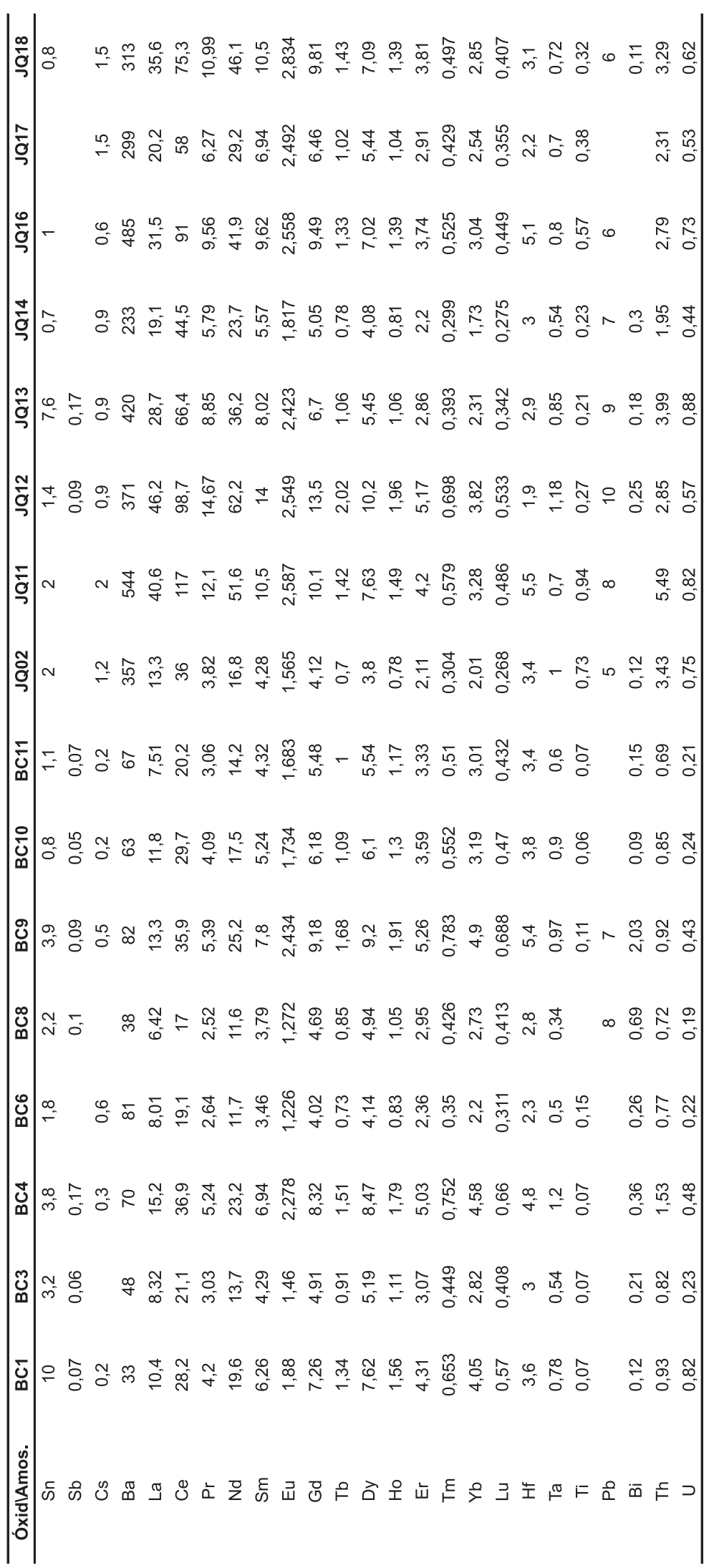


Através da leitura do diagrama AFM, de Irvine e Baragar (1971), fica claro o caráter toleiitico das amostras BC e JQ, com as BC menos evoluídas (Figura 6).

Os resultados analíticos obtidos mostram que os anfibolitos BC têm composição exclusivamente básica (48\% < $\mathrm{SiO} 2<51 \%$ - Tabela 1) e as correlações positivas $\mathrm{FeO}^{\mathrm{t}}, \mathrm{Ti}$ - FeOt/MgO, bem como os valores de Nb/Y (0,2 - 0,3), indicam que as rochas originais corresponderiam a basaltos/ doleritos (não orogênicos) de natureza toleiitica.

Nos diagramas de variação binários, utilizando como índice de diferenciação $\mathrm{MgO}$, em função da natureza basáltica das amostras analisadas, observa-se, claramente, a distinção entre os dois conjuntos de anfibolitos. Para os elementos maiores, na Figura 7, nota-se a disposição, em separado, das amostras BC e JQ, sendo que os dois conjuntos se distinguem quanto aos seguintes aspectos: primeiramente nota-se que as amostras BC apresentam maior intervalo composicional em MgO (5 - 9\%) e concentrações mais restritas em relação aos demais óxidos, enquanto os anfibolitos JQ têm uma variação menor em MgO (3 - 5\%) e maior amplitude de variação para $\mathrm{SiO}_{2}, \mathrm{P}_{2} \mathrm{O}_{5}, \mathrm{Na}_{2} \mathrm{O}$ e $\mathrm{K}_{2} \mathrm{O}$; outra característica refere-se à disposição antagônica das correlações entre $\mathrm{MgO}$ x $\mathrm{TiO}_{2}$ e $\mathrm{Fe}_{2} \mathrm{O}_{3}$ nos diferentes conjuntos - enquanto essas correlações se comportam de modo compatível com a evolução normal do fracionamento magmático e são positivas nas amostras BC, elas são negativas para as amostras JQ, nestes mesmos diagramas. No entanto, em função do pequeno intervalo de variação das concentrações em MgO das amostras JQ, esse comportamento

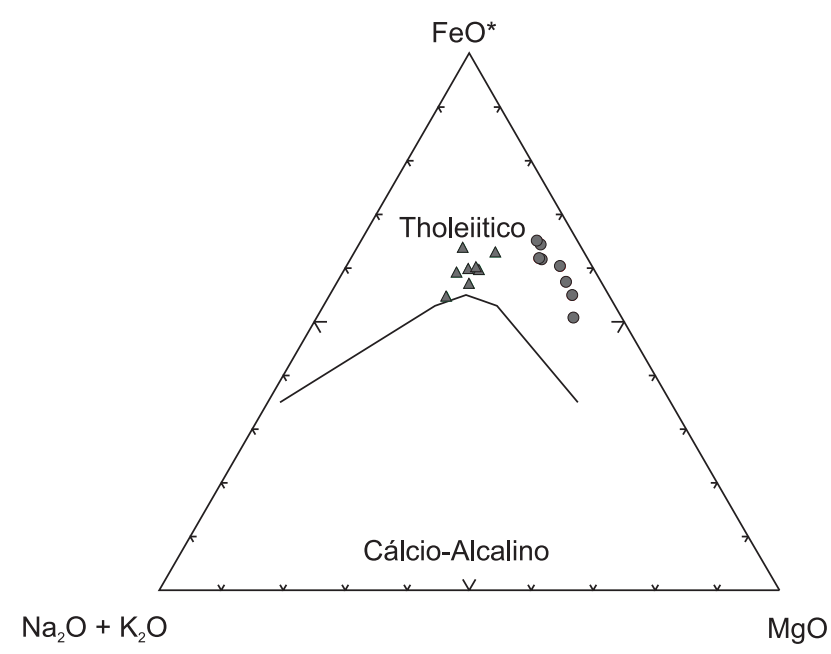

Figura 6. Diagrama AFM de Irvine e Baragar (1971) com os anfibolitos de Boissucanga BC (círculos) e de Juqueí JQ (triângulos). discrepante pode apenas refletir as diferenças no estágio de fracionamento dos líquidos correspondentes aos diferentes conjuntos de amostras. Comportamento compatível com a evolução da diferenciação é observado para $\mathrm{CaO}$, onde, tanto as amostras BC quanto as JQ, apresentam decréscimo nos teores deste óxido nas amostras mais diferenciadas.

Os diagramas de variação binários, para os elementos traços (Figura 8), permitem a separação evidente, em especial através do $\mathrm{Cr}$ e $\mathrm{Ni}$, com altos teores destes elementos, das amostras BC, com relação às demais. O comportamento caracteristicamente compatível do $\mathrm{Cr}$ e Ni dos anfibolitos BC contrasta com o comportamento incompatível evidenciado nos diagramas dos outros elementos, onde esta tendência é discreta somente para as amostras BC, na relação com o Ba.

Muito embora a gama das concentrações de elementos compatíveis (211 ppm < Ni < 18 ppm; 332 ppm < Cr $<57$ ppm) e dos valores de mg\# (44 - 59) sejam sugestivos da atuação de processos de cristalização fracionada na fonte, variações significativas nas razões entre elementos incompatíveis $(\mathrm{Zr} / \mathrm{Nb}=11$ - 23) sugerem que os anfibolitos BC, analisados, tenham sido levemente modificados durante o processo metamórfico a que foram submetidos.

Os diagramas de concentrações normalizadas por condrito (Boynton, 1984) dos ETR, das rochas anfibolíticas (Figura 9), apresentam dois padrões distintos, com assinaturas próximas dentro de cada conjunto. O padrão das rochas BC (Figura 9a), pouco fracionado, com discretas anomalias de Eu, tanto negativas como positivas, caracteriza rochas pouco diferenciadas. A assinatura geoquímica das amostras JQ (Figura 9b), apresentando um padrão pouco mais inclinado, com maior enriquecimento dos ETR leves e maior amplitude de distribuição, em relação aos pesados, pode indicar um maior fracionamento sofrido por estas rochas, relativamente às amostras anteriores (BC). Esse comportamento é característico dos processos de cristalização fracionada representados pelas porções gabroicas de complexos estratiformes, como os de Skaergaard e Stillwater (Haskin e Haskin, 1968; Paster et al., 1974; Lambert e Simmons, 1988), enquanto que as rochas gabroicas de ambientes oceânicos (ofiolitos) são caracteristicamente empobrecidas em ETR leves em relação aos pesados, conforme atestam os dados compilados por Suen et al. (1979) e Kay e Senechal (1976).

Os padrões de elementos terras raras (Figura 9a) dos anfibolitos BC mostram ligeiro enriquecimento em TR leves, relativamente às pesadas $\left(\mathrm{La} / \mathrm{Sm}_{\mathrm{cn}}=1,0-1,4 ; \mathrm{La} / \mathrm{Yb}_{\mathrm{cn}}\right.$ $=1,5-2,4)$, quando comparados com os padrões condríticos. Esse comportamento é observado em basaltos das dorsais meso-oceânicas tipo MORB-P (Sun e Nesbitt, 1979) e também se assemelha ao padrão descrito para alguns toleiitos continentais (Dupuy e Dostal, 1984). 

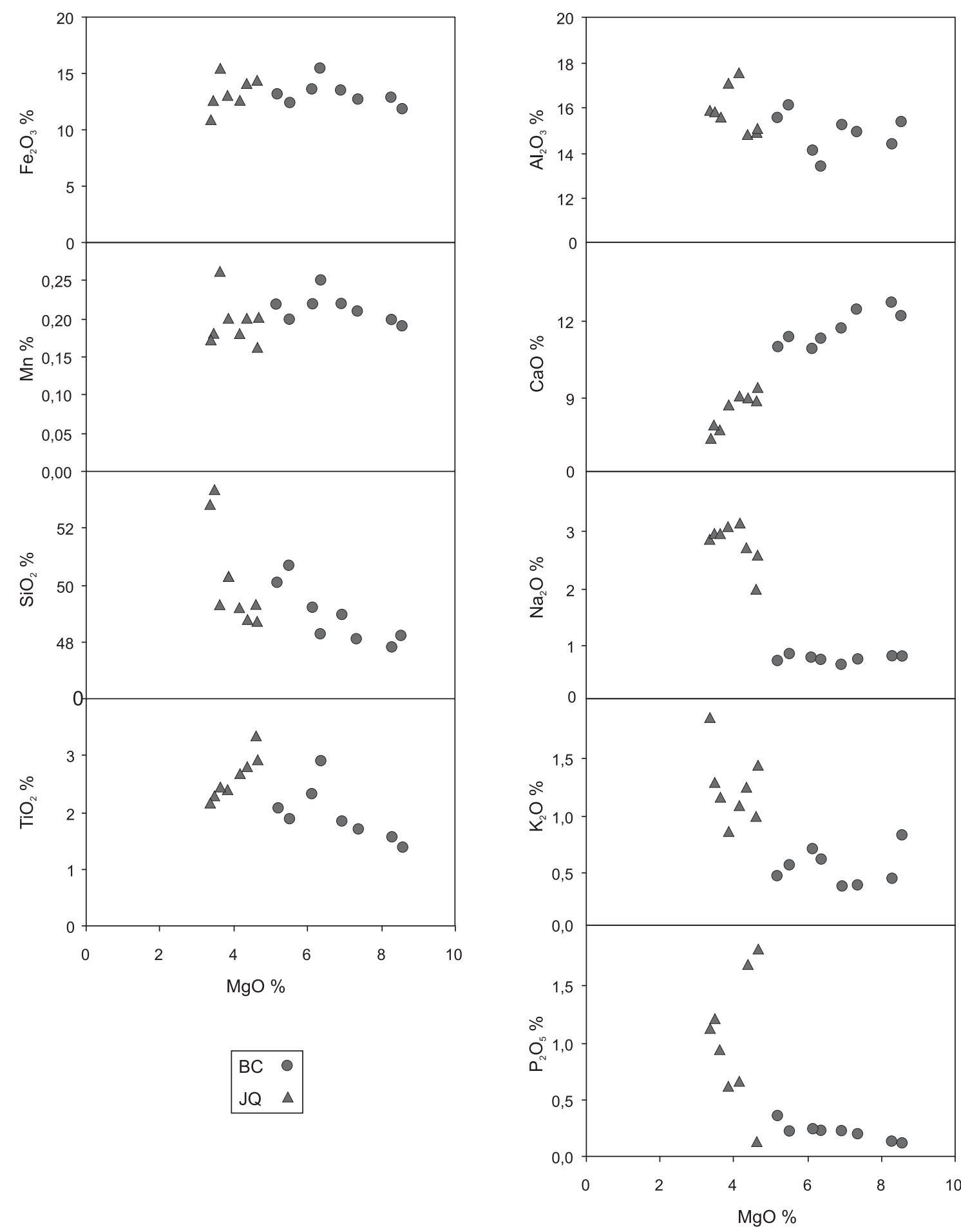

Figura 7. Diagramas de variação binários, com índice de diferenciação $\mathrm{MgO}$, para os elementos maiores. $\mathbf{B C}=$ anfibolitos Boissucanga; $\mathbf{J Q}=$ anfibolitos Juqueí. 

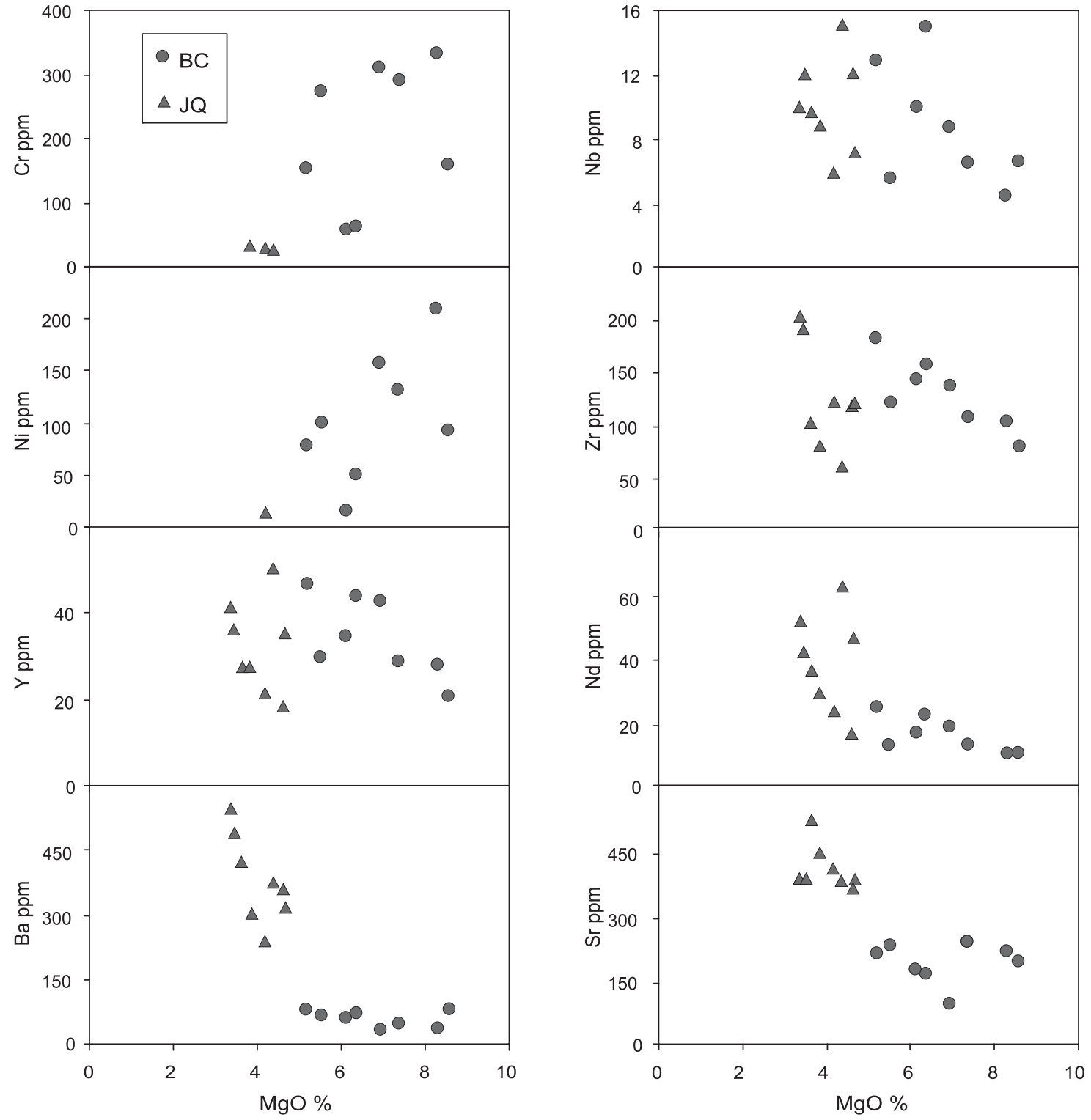

Figura 8. Diagramas de variação binários, com índice de diferenciação $\mathrm{MgO}$, para os elementos traços. $\mathbf{B C}=$ anfibolitos Boissucanga; $\mathbf{J Q}=$ anfibolitos Juqueí. 
- $\mathrm{BC}-01 \cdot \mathrm{BC}-03 \cdot \mathrm{BC}-04 \cdot \mathrm{BC}-06 \cdot \mathrm{BC}-08$

- $\mathrm{BC}-09 \cdot \mathrm{BC}-10 \bullet \mathrm{BC}-11$

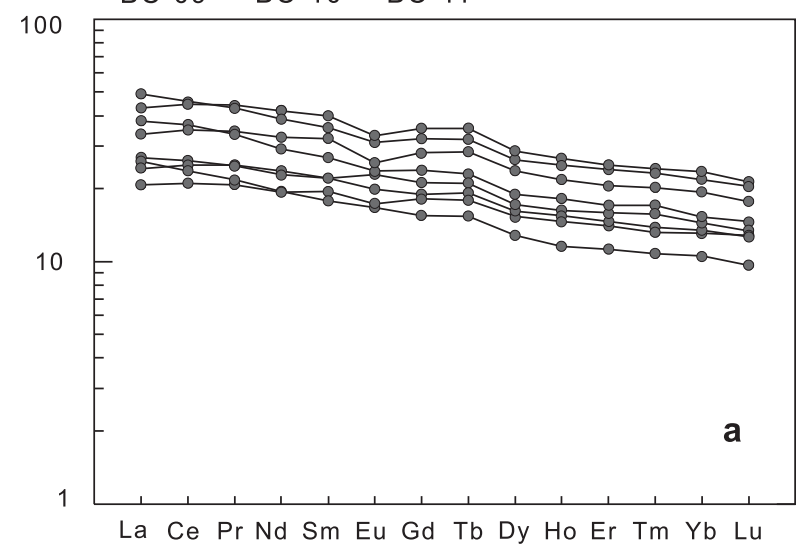

$\triangle J Q-02 \Delta J Q-11 \Delta J Q-12 \Delta J Q-13 \quad \Delta J Q-14$

$\Delta \mathrm{JQ}-16 \quad \Delta \mathrm{JQ}-17 \Delta \mathrm{JQ}-18$

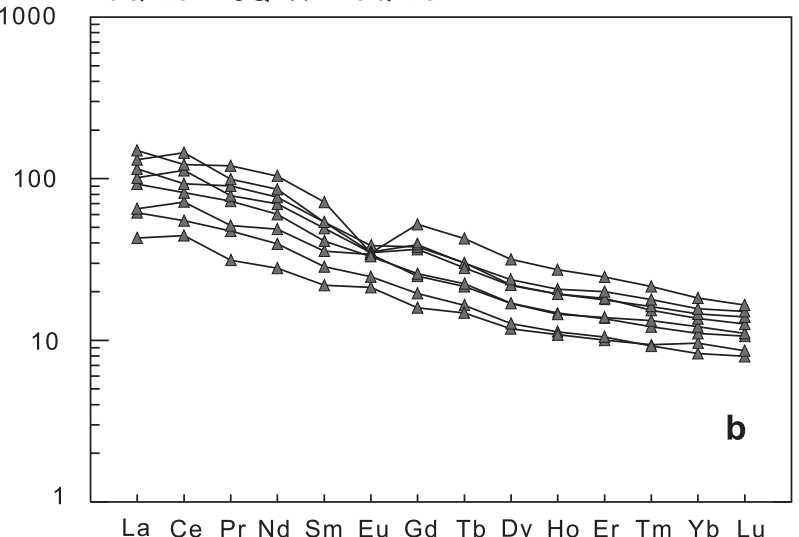

Figura 9. Diagramas de concentrações normalizadas para condrito (Boynton, 1984), de ETR dos anfibolitos de (a) Boissucanga $\mathrm{BC}$ e de (b) Juqueí JQ.

\section{DISCUSSÃO E CONSIDERAÇÕES FINAIS}

Os estudos desenvolvidos, nas diversas áreas do conhecimento geológico, permitiram esboçar o caminho evolutivo das rochas orto e para derivadas que constituem o Complexo Costeiro, na área de investigação.

Para o caso específico das amostras BC, foi possível o estabelecimento de uma interpretação mais completa. As relações geométricas destas rochas máficas com a encaixante sugerem que correspondam a diques ou "sills", de composição basáltica, "boudinados” e paralelizados com a estrutura gnáissica, representando atividade magmática pré-tectônica (Dias Neto et al., 1999). Contudo, a intensa deformação e o metamorfismo regional Neoproterozoico (atingindo localmente a fácies granulito) apagaram totalmente quaisquer vestígios da textura e mineralogia ígnea originais. Neste contexto, a geoquímica de elementos (relativamente) imóveis é utilizada para obter informações sobre a afinidade magmática e o ambiente geotectônico do magmatismo máfico pré-orogênico nesta região.

Em função dos aspectos texturais e das formas de ocorrência dos corpos anfibolíticos, considerou-se a possibilidade, em interpretações de campo, das rochas metagabroicas JQ representarem o produto da cristalização do material que teria permanecido em uma câmara magmática, a partir da qual teriam se originado as estruturas tabulares dos anfibolitos BC. O caráter menos evoluído das rochas BC, como demonstram os dados geoquímicos, não favorece esta abordagem.

Entretanto é possível considerar que os magmas que resultaram nas rochas JQ e BC, tenham tido uma origem comum a partir de uma câmara magmática primária. Nesse caso as estruturas tabulares BC poderiam representar de forma mais próxima a composição do líquido na câmara primária, mais rico em elementos compatíveis, enquanto o produto da cristalização em câmaras secundárias (JQ), onde seriam mais efetivos processos de fracionamento magmático, gerariam produtos empobrecidos nos elementos compatíveis como os padrões de Cr e Ni observados na Tabela 1 e na Figura 8.

O fato da distribuição dos ETR dos anfibolitos BC (Figura 9a), se aproximar daquela que caracteriza os termos menos evoluídos dos anfibolitos JQ (Figura 9b) reforça a suposição de origem comum. De modo equivalente, os teores mais elevados dos elementos Th, Ti (Figura 10) e Rb (Figura 11), dispostos em padrões de correlação positiva, tendo como posição de origem os anfibolitos BC, também sugerem essa hipótese.

Além disso, as observações de campo, indicando abundância de injeções pegmatíticas, entrecortando o corpo metagabroico de Juqueí, aliadas à presença marcante de biotitas e apatitas, como detectadas nas análises petrográficas e aparentes nas correlações positivas de $\mathrm{K}_{2} \mathrm{O}$ e $\mathrm{P}_{2} \mathrm{O}_{5}$ com Th (Figuras 12 e 13), quando se compara as duas ocorrências anfibolíticas, parecem indicar que as rochas JQ foram mais modificadas no contato com líquidos silicáticos, gerados por fusão parcial durante o processo metamórfico regional, enquanto as rochas BC teriam sido mais preservadas.

Essas modificações tardias, se de fato efetivas, só teriam reforçado as características anteriormente comentadas e condicionadas pelas possíveis diferentes formas de colocação dos magmas nos corpos BC e JQ. De qualquer 


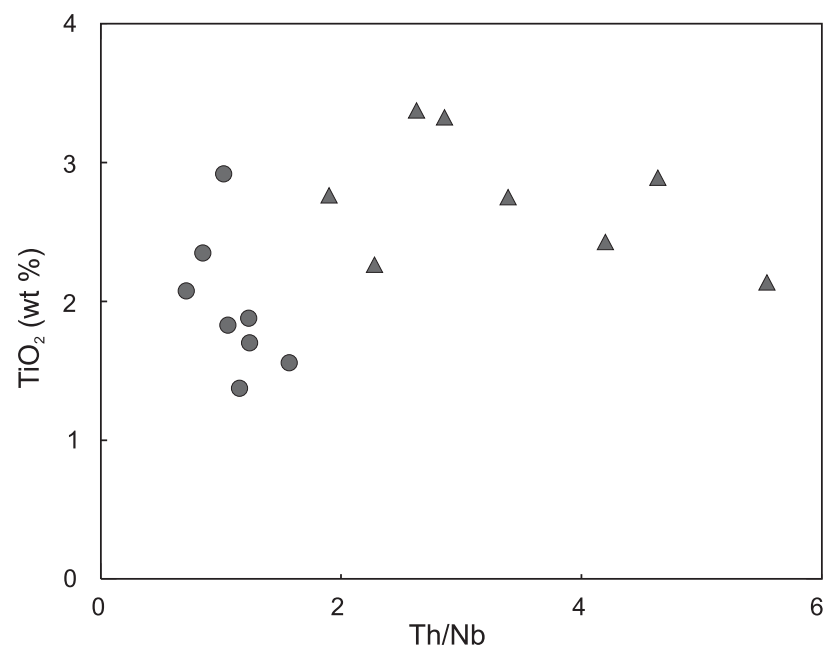

Figura 10. Relação entre a razão $\mathrm{Th} / \mathrm{Nb}$ e $\mathrm{TiO}_{2}(\%$ em peso) para os anfibolitos de Boissucanga $\mathrm{BC}$ (círculo) e Juqueí JQ (triângulo).

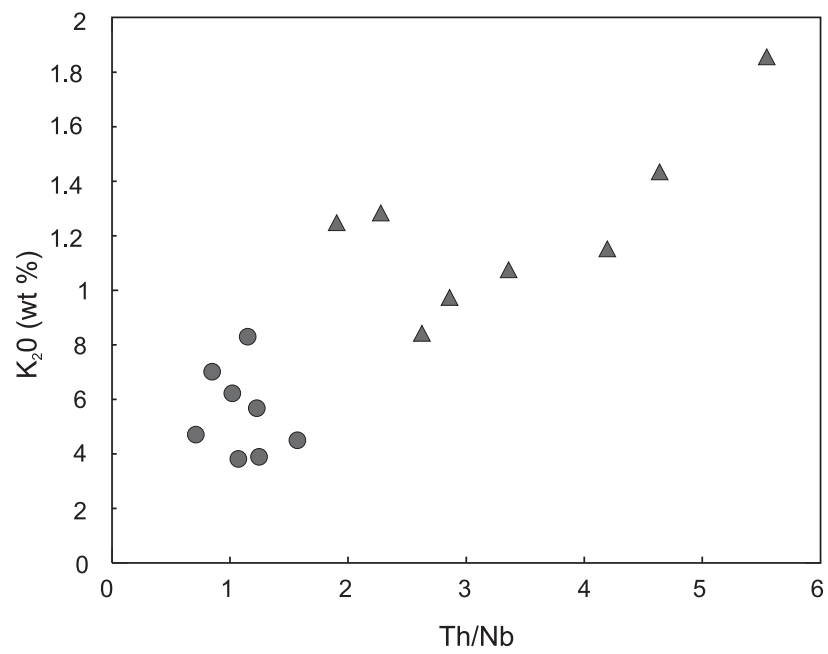

Figura 12. Relação entre a razão Th/ $\mathrm{Nb}$ e $\mathrm{K}_{2} \mathrm{O}$ (\% em peso) dos anfibolitos de Boissucanga BC (círculo) e de Juqueí JQ (triângulo).

modo, tanto pelo possível caráter mais fracionado, como pela possibilidade de interação com injeções magmáticas tardias, as inferências geoquímicas em relação às rochas JQ, devem ser feitas com maior cuidado e avaliadas com as devidas reservas.

Já as amostras BC, mais preservadas, possibilitam melhor caracterização quanto à origem e evolução. Conforme já apresentado, o comportamento dos elementos terras raras indicam, para esse conjunto, afinidades com basaltos tipo

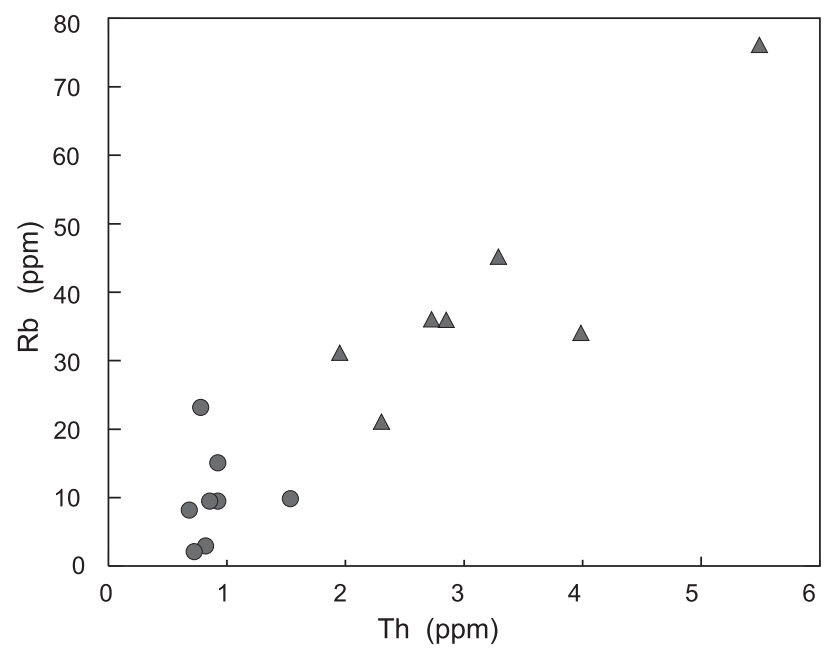

Figura 11. Relação entre Th (ppm) e Rb (ppm) dos anfibolitos de Boissucanga BC (círculo) e de Juqueí JQ (triângulo).

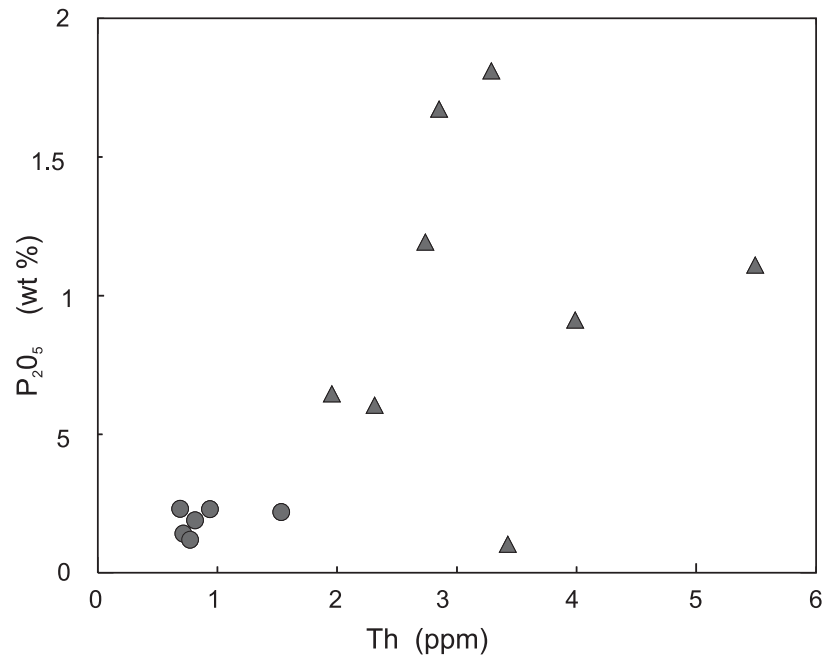

Figura 13. Relação entre a razão Th (ppm) e $\mathrm{P}_{2} \mathrm{O}_{5}(\%$ em peso) dos anfibolitos de Boissucanga $\mathrm{BC}$ (círculo) e de Juqueí JQ (triângulo).

MORB-P e com certos toleiitos continentais. No entanto, os espectros elementares das rochas BC, representados na Figura 14, mostram anomalias negativas nos elementos de alto potencial iônico (HFSE, ex.: Nb, Ti), relativamente aos litófilos (LILE, ex.: Th, La), La/Nb = 1,0 - 1,4, Th/Nb = 0,07 - 0,16, o que favorece caracterizar os anfibolitos de Boissucanga como representativos de toleiitos continentais (Dias Neto et al., 1999). De fato, a crosta continental menos refratária é enriquecida em LILE relativamente aos HFSE e 
a contaminação crustal de um magma MORB-P pode facilmente produzir os espectros característicos dos toleiitos continentais, ilustrados na Figura 14, em particular se o processo de contaminação corresponder ao mecanismo de mistura simples entre os magmas basálticos e os materiais supra crustais. A correlação positiva Th/Nb - Ni na Figura 15 suporta esta hipótese. Caso tivessem ocorrido mecanismos tipo ACF de De Paolo (1981) essa correlação não se verifi-

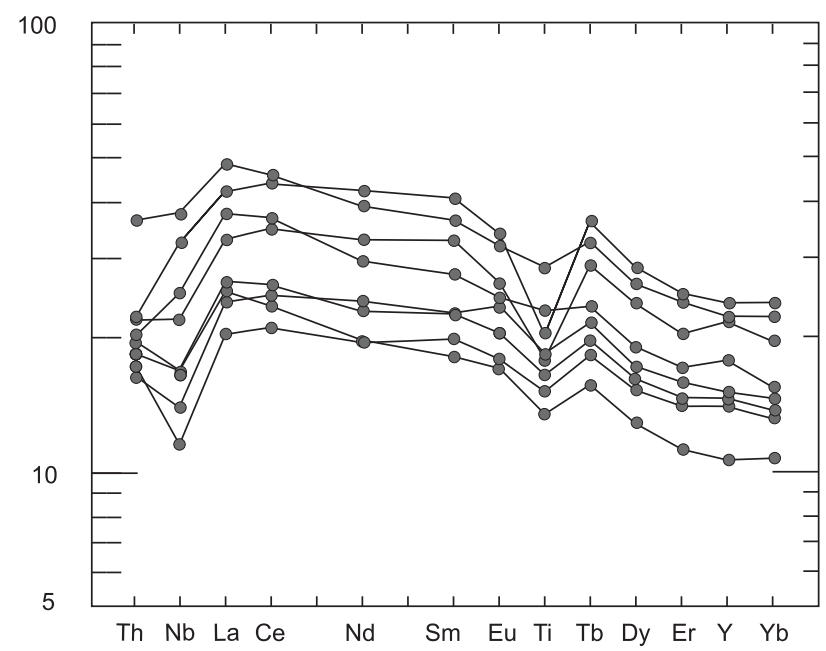

Figura 14. Diagrama de elementos incompatíveis normalizados dos anfibolitos de Boissucanga BC, ETR normalizado pelo condrito (Masuda et al., 1973) e Th, Nb, Ti e Y de acordo com Thompson et al. (1984).

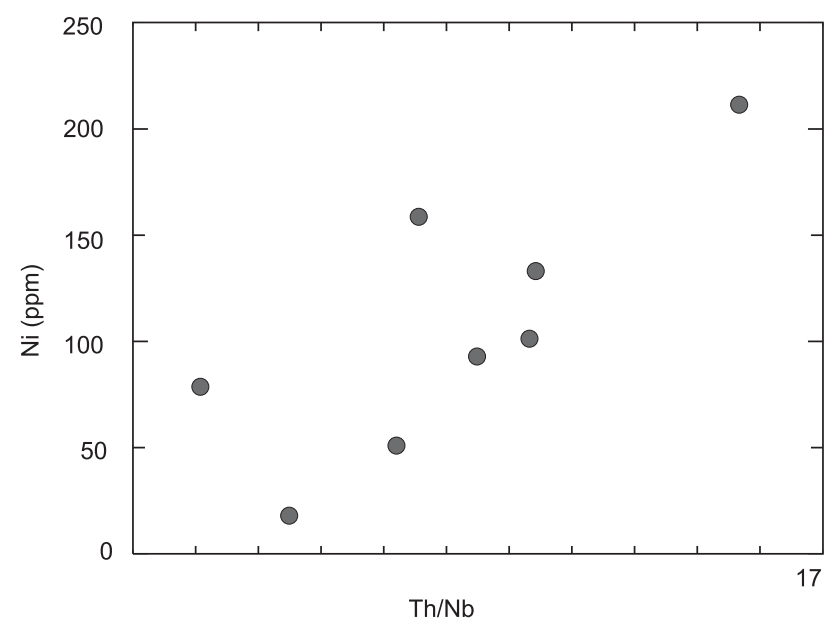

Figura 15. Relação entre $\mathrm{Ni}$ (ppm) e a razão $\mathrm{Th} / \mathrm{Nb}$, onde os anfibolitos de Boissucanga BC se organizam em correlação positiva. caria. Assim, na situação geológica em estudo, os magmas mais primitivos teriam certamente maior potencial energético para proceder à assimilação de crosta continental, sendo por isso, os mais contaminados, como se demonstra nas Figuras 14 e 15.

No Neoproterozoico-Eocambriano, em regime de convergência que estaria gerando o supercontinente Gondwana, as rochas desta região estiveram ambientadas, provavelmente, em um ambiente de bacia de retroarco, a julgar pela proximidade entre as idades U-Pb (SHRIMP; Dias Neto, 2001) do ápice metamórfico (571 \pm 10 Ma) com as da cristalização das intrusões das rochas máficas (BC 580 \pm 26 Ma; JQ $593 \pm 10$ Ma), que se transformaram nos núcleos anfibolíticos interiores aos paragnaisses, indicando um período muito curto, da ordem de $10 \mathrm{Ma}$, entre o metamorfismo de alto grau e o magmatismo máfico. A ocorrência destas intrusões ígneas, juntamente com a caracterização litoquímica das rochas BC enquanto toleiitos continentais, favorecem estas interpretações.

O possível arco magmático relativo a esse ambiente deve ter evoluído em uma época pouco anterior há 600 Ma, não tendo sido ainda localizadas, na área de estudo, rochas graníticas diferenciadas do manto superior no Neoproterozoico, que possam representar um arco magmático juvenil neste período de tempo. Os ortognaisses, situados no setor oeste da área estudada, que forneceram idades Rb-Sr próximas a esta época e caracterizados por parâmetros de $\varepsilon_{\mathrm{Nd}}$, calculados para $630 \mathrm{Ma}$, com valores de -6 a -7 (Dias Neto, 2001), indicando certo tempo de residência crustal, poderiam, eventualmente, caracterizar um arco magmático produzido por processos colisionais com envolvimento de fusão parcial de rochas continentais preexistentes.

\section{REFERÊNCIAS}

ALMEIDA, F. F. M.; AMARAL, G.; CORDANI U. G.; KAWASHITA, K. The precambrian evolution of the South American Cratonic Margin South of Amazonas River. In: NAIRN, A. E. M; STEHLI, F. G. (Eds.). The ocean basin and margins. New York: Plenum Press. 1973, v. 1, p. 411-446.

AMARAL, G.; BUSHEE, J.; CORDANI, U. G.; KAWASHITA, K.; REYNOLDS, J. H. Potassium-argon age of alkaline rocks from Southern Brazil. Geochimica et Cosmochimica Acta, v. 31, p. 117-142. 1967.

BERGMANN, M. Caracterização estratigráfica e estrutural da seqüência vulcano-sedimentar do Grupo São Roque, na região de Pirapora do Bom Jesus, Estado de São Paulo. 1988. 166 f. Dissertação (Mestrado) - Instituto de Geociências, Universidade de São Paulo, São Paulo, 1988. 
BRITO NEVES, B. B.; CORDANI, U. G. Tectonic evolution of South America during late proterozoic. Precambrian Research, v. 33, p. 23-40, 1991.

BOYNTON, W. R. Cosmochemistry of the rare earth elements meteorite studies. In: HENDERSON, P. (Ed.). Rare earth element geochemistry. Amsterdan: Elsevier, 1984. p. 3-114.

CAMPANHA, G. A. C.; ENS, H. H. Estrutura geológica na região de São Sebastião. In: SIMPÓSIO DE GEOLOGIA DO SUDESTE, 3., 1993, Rio de Janeiro. Boletim de Resumos... Rio de Janeiro: SBG, 1993. p. 51- 52.

CARNEIRO, C. D. R.; SANTORO, E.; RODRIGUES, E. P.; HASUI, Y. Evolução geológica do Pré-cambriano na baixada santista. In: SIMPÓSIO REGIONAL DE GEOLOGIA, 2., 1979, Rio Claro. Atas...Rio Claro: SBG, 1979. v 1, p. 31-45.

CHIODI FILHO, C.; CHIEREGATI, L. A; THEODOROVICZ, A. M. G.; THEODOROVICZ, A.; MENEZES, R. G.; RAMALHO, R.; BATOLLA JR., F. Geologia e recursos minerais das folhas de Natividade da Serra e Caraguatatuba. In: JORNADA SOBRE A CARTA GEOLÓGICA DO ESTADO DE SÃO PAULO EM 1:50 000, 1., São Paulo, 1983. Atas... São Paulo: Pró-Minério, IPT. p. 8-29.

CORDANI, U. G.; DELHAL, J.; LEDENT, D. Orogeneses superposeés dans le Précambrien du Brésil sud-oriental (États du Rio de Janeiro et de Minas Gerais). Revista Brasileira de Geociências, v. 3, n. 1, p. 1-22, 1973.

COUTINHO, J. M. V.; TASSINARI, C. C. G. The Embu and Costeiro metamórphic complexes: Southestern Brazil. In: INTERNATIONAL SEMINAR NEW TRENDS IN GEOLOGY, 1991, Sao Paulo. Geological Excursion... São Paulo: Instituto de Geociências, 1991. p. 1-9.

DE PAOLO, D. J. Trace element and isotopic effects of combined wallrock assimilation and fractional crystallization. Earth Planetary Science Letters, v. 53, p. 189-202, 1981.

DIAS NETO, C. M.; PALACIOS, T.; MUNHÁ, J. M. U.; TASSINARI, C. C. G.; CORREIA, C. T. Magmatismo préOrogênico no Cinturão Ribeira (SE do Brasil): geoquímica dos anfibolitos na região de Boissucanga. In: CONGRESSO DE GEOQUÍMICA DOS PAÍSES DE LÍNGUA PORTUGUESA, 5 / CONGRESSO BRASILEIRO DE GEOQUímICA, 7., 1999, Porto Seguro. Anais...Porto Seguro: SBGq, 1999. p. 486-488.
DIAS NETO, C. M. Evolução Tectono-termal do Complexo Costeiro (Faixa de Dobramentos Ribeira) em São Paulo. 2001. 160 f. Tese (Doutorado) - Instituto de Geociências, Universidade de São Paulo, São Paulo, 2001.

DIAS NETO, C. M.; FONSECA, P. E.; MUNHÁ, J.; EGYDIO SILVA, M.; RIBEIRO, A. A estrutura em flor (flower structure) do Complexo Costeiro (Faixa Ribeira) em São Sebastião (São Paulo, Brasil). Cadernos Laboratório Xeolóxico de Laxe, La Curuña, v. 31, p. 105-125, 2006.

DIAS NETO, C. M.; CORREIA, C. T.; MUNHÁ, J. M. U.; TASSINARI, C. C. G. Litoquímica dos granitóides da estrutura em flor de São Sebastião, São Paulo. Geologia USP: Série Científica, São Paulo, v. 8, n. 2, p. 101-114, 2008.

DUPUY, C.; DOSTAL, J. Trace element geochemistry of some continental tholeiites. Earth Planetary Science Letters, v. 67, p. 61-69,1984.

EBERT, H . Tectônica do Sul do Estado de Minas Gerais e regiões adjacentes. Relatório Anual do Diretor. DGM, DNPM., Rio de Janeiro, p. 97-107, 1957

EBERT, H. Ocorrência de fácies granulítica no Sul de Minas Gerais, e regiões adjacentes, em dependência da estrutura orogênica: hipóteses sobre sua origem. Anais da Academia Brasileira de Ciências, Rio de Janeiro, v. 40, p. 215-229. 1968. Suplemento.

EBERT, H. D.; HASUI, Y.; COSTA, J. B. S. O caráter transpressivo do cinturão transcorrente Rio Paraíba do Sul. In: SIMPÓSIO NACIONAL DE ESTUDOS TECTÔNICOS, 3., 1991, Rio Claro. Boletim de Resumos Expandidos... Rio Claro: SBG, 1991. p. 139 -141.

EBERT, H. D.; NEVES, M. A.; HASUI, I.; SZATMARI, P.; AIRES, J. R. Evolução dos cinturões de cisalhamento entre os blocos São Paulo, Vitória e Brasília através da tectônica colisional oblíqua: uma modelagem física. In: SIMPÓSIO NACIONAL DE ESTUDOS TECTÔNICOS, 4., 1993, Belo Horizonte. Anais... Belo Horizonte: SBG, 1993. p. 254-258.

EBERT, H. D.; HASUI, Y. Transpressional tectonics and strain partitioning during oblique collison between three plates in Precambrian of south-east Brazil. In: HOLDSWORTH, R. E.; STRACHAN, R. A.; DEWEY, J. F. (Eds.) Continental transpressional and transtensional tectonics. London: Geological Society, 1998. p. 231-253. (Geological Society Special Publication, 135). 
FIGUEIREDO, M.; BERGMANN, M.; PENALVA, F.; TASSINARI, C. C. G. Ocorrência de "pillow lavas" no Grupo São Roque, Estado de São Paulo. Ciências da Terra, v. 2, p. 6-8, 1982.

FONSECA, M. J. G.; SILVA, Z. C. G.; CAMPOS, D. A.; TOSATTO, P. Folhas do Rio de Janeiro, Vitória e Iguape: texto explicativo. Brasília: DNPM. 1979. 239 p.

HACKSPACHER, P.; DANTAS, E. L.; SPOLADORE, A; FETTER, A. H.; OLIVEIRA, M. A. F. Evidence of Neoproterozoic backarc basin development in the Central Ribeira Belt, Southeastern Brazil: new geochronological and geochemical constrains from the São Roque-Açungui Groups. Revista Brasileira de Geociências, v. 30, n. 1, p. $110-114,2000$.

HASKIN, L. A.; HASKIN, M. A. Rare-earth elements in the Skaergaard intrusion. Geochimica et Cosmochimica Acta, v. 32, p. 433-47, 1968.

HASUI, Y.; SADOWSKI, G. R. Evolução Geológica do Pré-Cambriano na região sudeste do Estado de São Paulo. Revista Brasileira de Geociências, v. 6, n. 3, p. 180-200, 1976.

HASUI, Y.; DANTAS, A. S. L.; CARNEIRO, C. D. R.; BISTRICHI, C. A. O embasamento Pré-Cambriano e Eopaleozóico em São Paulo. In: Mapa Geológico do Estado de São Paulo. Pró-Minério, IPT. v. 1, p. 12-45, 1981.

IRVINE, T. N.; BARAGAR, W R. A. A guide to the chemical classification of the common volcanic rocks. Canadian Journal of Earth Sciences, v. 8, p. 523-548, 1971.

JANASI, V. A.; ULBRICH, H. H. G. J. Inventário bibliográfico de granitos do Estado de São Paulo. Boletim IGUSP. Publicação Especial, n. 11, p. 1-253, 1992.

JULIANI, C.; HACKSPACHER, P.; DANTAS, E. L.; FETTER, A. H. The Mesoproterozoic vulcano-sedimentay Serra do Itaberaba Group of Central Ribeira Belt, São Paulo State, Brazil: implications for the age of the overlying São Roque Group. Revista Brasileira de Geociências, v. 30, n. 1, p. 82-86, 2000.

KAY, R. W.; SENECHAL, R. G. The rare earth geochimistry of the troodos ophiolite complex. Journal of Geophysical Research, v. 81, n. 5, p. 964-70, 1976.

LAMBERT, D. D.; SIMMONS, E. C. Magma evolution in the Stillwater Complex, Montana: II. Rare earth element evidence for the Formation of the J-M Reef. Economic Geology and the Bulletin of the Society of Economic Geologists, v. 83, n. 6, p. 1109-26, 1988.

LAZZARI, J. L. O metabasito de Pirapora do Bom Jesus. 1987. 84 f. Dissertação (Mestrado) - Instituto de Geociências, Universidade de São Paulo, São Paulo, 1987.

LE MAITRE, R. W. A classification of igneous rocks and glossary of terms. Oxford: Blackwel. 1989. 193 p.

MACHADO, R.; ENDO, I. A mega estrutura em flor positiva do vale do rio Paraíba do Sul no Rio de Janeiro e suas implicações tectônicas regionais. In: SIMPÓSIO DE GEOLOGIA DO SUDESTE, 3., 1993. Rio de Janeiro. Atas... Rio de Janeiro: SBG, 1993. p. 208-213.

MASUDA, A.; NAKAMURA, M.; TANAKA, T. Fine structures of mutually normalized rare-earth patterns of chondrites. Geochimica et Cosmochimica Acta, v. 37, p. 239-248, 1973.

MINIOLI, B. Determinações potássio-argônio em rochas localizadas no litoral Norte do Estado de São Paulo. Anais da Academia Brasileira de Ciências, v. 43, n. 2, p. 443-448, 1971.

PASTER, P.; SCHAUWECKER, S. D.; HASKIN, L. The behavior of some trace element during solidification of the Skaergaard layered series. Geochimica et Cosmochimica Acta, v. 38, p. 1549-77, 1974.

ROSIER, G. F. Pesquisas geológicas na parte oriental do Estado do Rio de Janeiro e na parte vizinha de Minas Gerais. Boletim. Departamento Nacional da Produção Mineral. Divisão de Geologia e Mineralogia, Rio de Janeiro, n. 222, p. 1-40. 1965.

SADOWSKI, G. R. A megafalha de Cubatão no sudeste brasileiro. Boletim Instituto de Geociências. Série Científica, v. 22, p. 15-28, 1991.

SILVA, A. T. S. F.; ALGARTE, J. P.; CHIODI FILHO, C.; CHIODI, D. K.; FERNANDES, N. A. O Complexo Bairro do Marisco (Caraguatatuba-SP). In: SIMPÓSIO DE GEOLOGIA REGIONAL, 1., 1977, São Paulo. Anais... São Paulo: SBG, 1977. p. 74-90.

SOBREIRO NETO, A. F.; PAIVA FILHO, A.; MORTARI, J. L.; BITAR, O. Y. Geologia da Folha São Luiz do Paraitinga (SP). In: JORNADA SOBRE A CARTA GEOLÓGICA DO ESTADO DE SÃO PAULO EM 1:50.000, 
1., São Paulo, 1983. Atas... São Paulo: Pro-Minério/ IPT, 1983. p. 31-52.

SUEN, C. J.; FREY, F. A.; MALPAS, J. Bay of Islands ophiolite suite, Newfoundland: petrologic and geochimical characteristics with emphasis on rare earth element geochimistry. Earth Planetary Science Letters, v. 45, p. 337-48. 1979.

SUN, S.; NESBITT, R. W. Geochemical characteristics of mid-ocean ridge basalt. Earth Planetary Science Letters, v. 44, p. 119-138, 1979.

TASSINARI, C. C. G.; CAMPOS NETO, M. C. Precambrian continental crust evolution of sotheastern São Paulo State-Brazil: based on isotopic evidences. Geochimica Brasiliensis, v. 2, n. 2, p. 175-183, 1988.

TASSINARI, C. C. G.; MUNHÁ, J. M. U.; RIBEIRO, A.; CORREIA, C. T. Neoproterozoic oceans in the Ribeira Belt (Southeastern Brazil) the Pirapora do Bom Jesus Ophiolitic Complex. Episodes, v. 24, n. 4, 2001.

ULBRICH, H. H. G. J.; GOMES, C. B. Alkaline rocks from continental Brazil. Earth-Science Reviews, v. 17, p. 135-154, 1981.

THOMPSON, R. N.; MORRISON, M. A.; HENDRY, G. L.; PARRY, S. J. An assessment of the relative roles of crust and mantle in magma genesis: an elemental approach. Philosophical Transaction Royal Society, London, Serie A, v. 310, p. 549-590, 1984. 